\title{
Effects of physical exercise interventions in frail older adults: a systematic review of randomized controlled trials
}

Carmen de Labra ${ }^{1}$, Christyanne Guimaraes-Pinheiro ${ }^{2}$, Ana Maseda ${ }^{2}$, Trinidad Lorenzo ${ }^{1}$ and José C. Millán-Calenti ${ }^{*}$ (i)

\begin{abstract}
Background: Low physical activity has been shown to be one of the most common components of frailty, and interventions have been considered to prevent or reverse this syndrome. The purpose of this systematic review of randomized, controlled trials is to examine the exercise interventions to manage frailty in older people.

Methods: The PubMed, Web of Science, and Cochrane Central Register of Controlled Trials databases were searched using specific keywords and Medical Subject Headings for randomized, controlled trials published during the period of 2003-2015, which enrolled frail older adults in an exercise intervention program. Studies where frailty had been defined were included in the review. A narrative synthesis approach was performed to examine the results. The Physiotherapy Evidence Database (PEDro scale) was used to assess the methodological quality of the selected studies.

Results: Of 507 articles, nine papers met the inclusion criteria. Of these, six included multi-component exercise interventions (aerobic and resistance training not coexisting in the intervention), one included physical comprehensive training, and two included exercises based on strength training. All nine of these trials included a control group receiving no treatment, maintaining their habitual lifestyle or using a home-based low level exercise program. Five investigated the effects of exercise on falls, and among them, three found a positive impact of exercise interventions on this parameter. Six trials reported the effects of exercise training on several aspects of mobility, and among them, four showed enhancements in several measurements of this outcome. Three trials focused on the effects of exercise intervention on balance performance, and one demonstrated enhanced balance. Four trials investigated functional ability, and two showed positive results after the intervention. Seven trials investigated the effects of exercise intervention on muscle strength, and five of them reported increases; three trials investigated the effects of exercise training on body composition, finding improvements in this parameter in two of them; finally, one trial investigated the effects of exercise on frailty using Fried's criteria and found an improvement in this measurement. Exercise interventions have demonstrated improvement in different outcome measurements in frail older adults, however, there were large differences between studies with regard to effect sizes.
\end{abstract}

Conclusions: This systematic review suggested that frail older adults seemed to benefit from exercise interventions, although the optimal program remains unclear. More studies of this topic and with frail populations are needed to select the most favorable exercise program.

Keywords: Exercise, Frail elderly, Physical activity, Functional capacity, Systematic review, Randomized controlled trial

\footnotetext{
*Correspondence: jcmillan@udc.es

${ }^{2}$ Gerontology Research Group, Department of Medicine, Faculty of Health

Sciences, Universidade da Coruña, Campus de Oza, E-15071 A Coruña, Spain

Full list of author information is available at the end of the article
} 


\section{Background}

According to the World Health Organization (WHO) [1], the proportion of people older than 60 is growing more rapidly than any other age group. Within this group, not everyone reaches old age successfully. Although the common rule is that increasing age is related to decreasing well-being and increasing levels of frailty $[2,3]$, it is also true that individuals with the same chronological age can vary in health and functional status [4].

The definition of frailty attempts to explain this discordance, and to do so, researchers can apply different approaches. One of them relates frailty to a physical phenotype describing only physical components [2]. According to this definition, the frailty syndrome is based on the presence of three or more of the following criteria: shrinking, weakness, poor endurance, energy slowness, and a low physical activity level. This frailty phenotype is the most extensively used assessment in different settings [5], and it classifies people into three main conditions: non-frail, pre-frail, and frail. Other definitions go beyond this one and encompass psychological components, such as having difficulties in activities of daily living (ADLs), for example, and psychological and social dimensions [6].

Frailty is a multidimensional concept that influences several domains, such as gait, mobility, balance, muscle strength, motor processing, cognition, nutrition, endurance and physical activity [7], and it is directly related to adverse consequences, such as falls, disability, the need for longterm care, hospitalization, and even mortality $[2,6,8]$. These adverse outcomes constitute a source of considerable healthcare expenditure, and it is known that the reduction of adverse outcomes could lead to an offset in medical costs [9]. In this sense, the clinical outcomes related to frailty should be treated to prevent the socioeconomic burden associated with this condition.

There is evidence suggesting that frailty is a potentially modifiable dynamic process characterized by frequent transitions between states over time. This definition suggests that specific interventions and health strategies could be used to prevent, postpone or even reverse the frailty phenomenon [10]. The American College of Sports Medicine's (ACSM) [11] position states that participation in regular physical activity elicits a number of favorable responses that contribute to healthy aging. In this sense, physical exercise has demonstrated its beneficial effects in reducing the risk of many adverse outcomes, such as frailty [12], the number of falls [13, 14], poor mental health $[15,16]$, decreased cognitive function [17], decreased cardiac and pulmonary function [18-20], decreased physical function, such as balance $[13,21,22]$, gait [21] and mobility [23], and poor muscular power and functional capacity [13, 24]. All of this accumulated evidence indicates that physical exercise, either in its aerobic or strength form, is fully recommended both in healthy older adults and in elderly people with chronic diseases and disabilities [11].

Although numerous interventions have been developed to improve the outcomes of frail elderly people, a major obstacle found by researchers to success in such interventions has been the difficulty of comparing the studies retrieved, due to the differences in the diagnosis of frailty. Considering this difficulty and assuming that exercise training produces beneficial effects in the elderly, the major goal of this systematic review of randomized, controlled trials (RCTs) was to investigate the benefits of exercise programs in frail elderly people, considering only those studies where frailty had been defined.

\section{Methods}

\section{Data sources and search strategy}

An extensive literature search of electronic databases, including PubMed, Web of Science and the Cochrane Central Register of Controlled Trials, was performed in three phases. In the first phase, without limiting the years of the search and introducing the search terms "aging", "frailty", "frail elderly", "aerobic exercise" and "strength exercise", we extracted the theoretical framework that is used as the basis for the current review. In the second phase (started in January 2013), the search was restricted to the last 10 years (January 2003-December 2012). Later, in the third phase, an updating of the literature (from January 2013 to June 2015) was performed. In the second and third phase, to select RCTs in which the intervention was performed with aerobic or resistance training in frail older people, we searched articles using the following keywords and Medical Subject Headings: [(randomized controlled trial) AND (frail elderly) AND (aerobic exercise) OR (randomized controlled trial) AND (frail elderly) AND (strength OR resistance exercise)].

\section{Inclusion criteria and quality assessment}

Based on the titles, abstracts and some parts of the articles when needed, we screened the literature to select those articles meeting the inclusion criteria. We described all of the studies that met the inclusion criteria according to the following:

Subjects: Frail elderly people, defined with a clear operational definition/measurement of frailty;

Study design: Original analysis of an RCT citing some type of aerobic or resistance training intervention for the intervention group(s) (IGs), and the control group (CTL) receiving no treatment, maintaining its habitual lifestyle or a home-based low level exercise program; 
Outcomes: Studies examining, as a primary outcome, the effects of the intervention on the domains of frailty and/or physical capacity and/or functional capacity of the sample; and

Language: Only publications in English were considered.

Exclusion criteria: Duplicated studies, non RCTs, studies in which both aerobic and resistance training coexisted in the intervention, secondary analysis of data sets, abstracts, reviews, descriptive studies and studies based on the description of a protocol, and studies based on the point of view of the authors were excluded. However, those studies in which aerobic training was included in the warm up or cool down and interventions based on resistance training, and vice versa, were included for review.

Data extraction was standardized according to the following terms: (i) design; (ii) objective; (iii) sample characteristics; (iv) type, intensity, frequency, and duration of the intervention; (v) measurement tools; and (vi) findings. Because of the heterogeneity of the study designs, a narrative synthesis approach was performed to examine the results, rather than a meta-analysis. Cohen's $d$ values were reported as indicators of effect size (ES). We interpreted the importance of the ES using the benchmarks for "small ES" $(d=0.2)$, "medium ES" $(d=0.5)$ and "large ES" $(d=0.8)$ offered by Cohen (1988) [25].

The methodological quality of each RCT was rated using the Physiotherapy Evidence Database (PEDro) scale [26]. The PEDro scale is an instrument for the methodological quality assessment of RCTs in physical therapy and exercise studies. The items on the PEDro scale were derived from a Delphi consensus procedure [27], and there are 11 items (see Table 1). The PEDro scale scores can range from 0 to 10, with a higher score indicating better methodological quality. Responses to items 2 to 11 are summed to create a total score, and item 1 relates to external validity. The reliability of this scale was evaluated with acceptable good results in intraclass correlation coefficients $0.56-0.91$ [26, 28]. Judgment by two independent raters was compared and, when necessary, discussed.

Ethical approval was noted for all of the published papers included in this review.

\section{Results}

\section{Study selection}

Figure 1 summarizes the results of the different steps to identify appropriate articles for the review. The Preferred Reporting Items for Systematic Reviews and Meta-Analyses (PRISMA) Statement was followed [29, 30] (see Additional file 1). The database search identified 507 articles, and after duplicate removal, 308 were considered potentially relevant and were screened for relevant content. From them, 226 were excluded on the basis of the title and the abstract, and 82 were retrieved for full-text assessment of eligibility. In the next phase, 73 of the 82 full-text articles were excluded based on the inclusion criteria. Forty trials were excluded for not meeting the setting characteristics: six for not meeting the study design, five for not meeting the study objective, and 22 for not meeting the type of training characteristics. Finally, nine studies met the inclusion criteria and were included in this review.

\section{Methodological quality}

PEDro scores ranged from 4 to 8 points, with a mean score of 7.1 (Table 1). All of the selected studies but one [31] scored 6 or more, indicating the high quality of the selected trials. All of the studies except for one [31] specified the eligibility criteria. In all of the studies, the subjects were randomly allocated to groups, and seven of them had concealment of allocation [13, 32-37]. Seven studies showed the similarities at baseline [32-38]. None of the trials had blinded participants or therapists, and seven had blinded assessors [13, 31, 32, 34-37]. Eight trials had retention rates of $85 \%$ or greater [13,32-38], and all of the studies met the intention-to-treat analysis criteria. All of the studies applied statistical analysis to group differences, and eight of them reported point estimates and measurements of variability [13, 32-38]. No studies were excluded on the basis of their methodological quality (see Table 1 ).

\section{Participants and study characteristics}

The included articles encompassed a sample of 1067 older people ( $71.8 \%$ women), with a mean age of $82.5 \pm 4.3$ years old. A total of 562 participants were community-dwelling elders, 262 lived in residential care facilities, and 243 were recruited from an acute care and rehabilitation teaching hospital. The identification of frail older people was based on Fried's criteria [13, 31, 33, 37], on indicators adapted from Fried's criteria [32], on Winograd's frailty scale [36], on a modified Physical Performance Test score, reporting the difficulty and/or assistance with up to two instrumental activities of daily living and/or one basic activity of daily living, and a peak aerobic power between 10 and $18 \mathrm{~mL} \mathrm{~kg}^{-1} \mathrm{~min}^{-1}$ [38], on two tests of physical abilities, and according to two questions from the Center for Epidemiological Studies depression scale [34, 35].

Four studies were conducted in Europe [13, 32, 34, 35], two in Australia/Oceania [33, 36], one in the United States of America [38], one in Brazil [31], and the last one in Asia [37]. While four studies did not have follow-up measurements after the intervention [13,31,33, 38], five studies recorded follow-up measurements ranging from 4 to 
Table 1 PEDro scale rating [26]

\begin{tabular}{|c|c|c|c|c|c|c|c|c|c|c|c|c|}
\hline Reference & $\begin{array}{l}\text { Eligibility } \\
\text { criteria }\end{array}$ & $\begin{array}{l}\text { Random } \\
\text { allocation }\end{array}$ & $\begin{array}{l}\text { Concealed } \\
\text { allocation }\end{array}$ & $\begin{array}{l}\text { Group similar } \\
\text { at baseline }\end{array}$ & $\begin{array}{l}\text { Blinded } \\
\text { subjects }\end{array}$ & $\begin{array}{l}\text { Blinded } \\
\text { therapist }\end{array}$ & $\begin{array}{l}\text { Blinded } \\
\text { assessors }\end{array}$ & $\begin{array}{l}\text { Less than } \\
15 \% \text { dropouts }\end{array}$ & $\begin{array}{l}\text { Intention-to-treat } \\
\text { analysis }\end{array}$ & $\begin{array}{l}\text { Between-group } \\
\text { comparisons }\end{array}$ & $\begin{array}{l}\text { Point measure } \\
\text { and variability }\end{array}$ & PEDro score \\
\hline Binder 2005 [38] & 1 & 1 & 0 & 1 & 0 & 0 & 0 & 1 & 1 & 1 & 1 & 6 \\
\hline Cadore 2014 [13] & 1 & 1 & 1 & 0 & 0 & 0 & 1 & 1 & 1 & 1 & 1 & 7 \\
\hline Faber 2006 [32] & 1 & 1 & 1 & 1 & 0 & 0 & 1 & 1 & 1 & 1 & 1 & 8 \\
\hline Fairhall 2014 [33] & 1 & 1 & 1 & 1 & 0 & 0 & 0 & 1 & 1 & 1 & 1 & 7 \\
\hline Giné-Garriga 2010 [34] & 1 & 1 & 1 & 1 & 0 & 0 & 1 & 1 & 1 & 1 & 1 & 8 \\
\hline Giné-Garriga 2013 [35] & 1 & 1 & 1 & 1 & 0 & 0 & 1 & 1 & 1 & 1 & 1 & 8 \\
\hline Kim 2015 [37] & 1 & 1 & 1 & 1 & 0 & 0 & 1 & 1 & 1 & 1 & 1 & 8 \\
\hline Latham 2003 [36] & 1 & 1 & 1 & 1 & 0 & 0 & 1 & 1 & 1 & 1 & 1 & 8 \\
\hline Lustosa 2011 [31] & 0 & 1 & 0 & 0 & 0 & 0 & 1 & 0 & 1 & 1 & 0 & 4 \\
\hline Total & 8 & 9 & 7 & 7 & 0 & 0 & 7 & 8 & 9 & 9 & 8 & 7.1 \\
\hline
\end{tabular}




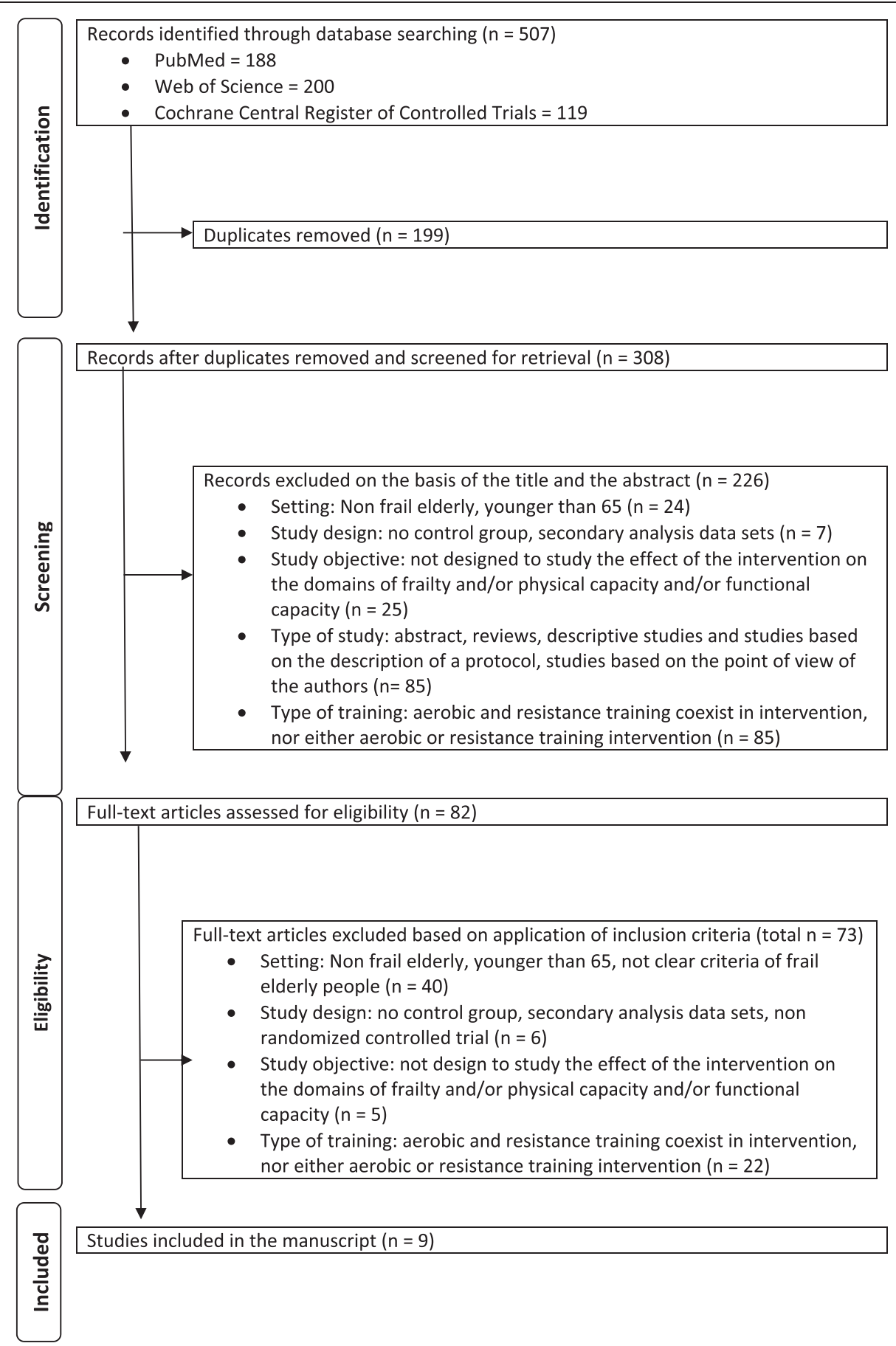

Fig. 1 Flow diagram of study selection

12 months [32, 34-37]. With regard to the type of intervention, the core of the selected articles was centered on resistance training exercises [13, 31-38] (Table 2).

\section{Intervention characteristics}

The intervention characteristics are summarized in Table 2. Six studies included multi component exercise interventions [13, 32-35, 38]. In two of these six studies, the intervention program involved progressive resistance exercise training (PRT) [13, 38]: one used an intervention home program of balance and strength, based on the Weight-bearing for Better Balance (WEBB) program [33]; one investigated two exercise programs, functional walking, consisting of exercises related to daily mobility 
Table 2 Characteristics of the included studies

\begin{tabular}{|c|c|c|c|c|c|c|}
\hline Reference & Sample & Setting & Identification of frailty & Intervention characteristics & Outcome measures & Findings (Cohen's $d$ ) \\
\hline $\begin{array}{l}\text { Binder } \\
2005 \text { [38] }\end{array}$ & $\begin{array}{l}n=91 \text { from } \\
\text { the USA Age, } \\
\text { mean } \pm \text { SD: } \\
83.0 \pm 4.0 \\
54 \% \text { women }\end{array}$ & $\begin{array}{l}\text { Community } \\
\text { dwelling }\end{array}$ & $\begin{array}{l}\text { Screening instruments and } \\
\text { procedures [12]: Modified } \\
\text { Physical Performance Test } \\
\text { score between } 18 \text { and } 32 \\
\text { (maximum } 36 \text { ); reporting } \\
\text { the difficulty and/or } \\
\text { assistance with up to two } \\
\text { instrumental and/or one } \\
\text { basic ADL; and a peak aerobic } \\
\text { power between } 10 \text { and } \\
18 \mathrm{~mL} \mathrm{~kg}^{-1} \mathrm{~min}^{-1}\end{array}$ & $\begin{array}{l}\text { Multi-component PRT } \\
\text { 9 months } \\
\text { 3/week } \\
60-90 \text { min/session } \\
\text { Initial goal: } \\
\quad 1-2 \text { sets } \\
\text { 6-8 repetitions } \\
\text { 65\% 1-RM } \\
\text { Final goal: } \\
\quad 3 \text { sets } \\
\text { 8-12 repetitions } \\
\text { 40-60\% 1-RM } \\
\text { 1-RM strength in six } \\
\text { different exercises } \\
\text { (knee extension, knee } \\
\text { flexion, seated bench } \\
\text { press, seated row, leg } \\
\text { press, biceps curl), } \\
\text { performed bilaterally } \\
\text { in a weightlifting } \\
\text { machine } \\
\text { Upper and lower extremities }\end{array}$ & $\begin{array}{l}\text { Strength: skeletal muscle strength } \\
\text { (maximal voluntary muscle strength } \\
\text { for knee extension and flexion) } \\
\text { Body composition: Total body DEXA }\end{array}$ & $\begin{array}{l}\text { Significant increase in } \\
\text { knee extension with the } \\
\text { intervention ( }(d=0.62) \\
\text { Knee flexion strength } \\
\text { showed no effect with the } \\
\text { interventionlntervention } \\
\text { induced greater increases } \\
\text { in total }(d=0.20) \text { and regional } \\
(d=0.19) \text { FFM but no changes } \\
\text { in fat mass }\end{array}$ \\
\hline $\begin{array}{l}\text { Cadore } \\
2014 \text { [13] }\end{array}$ & $\begin{array}{l}n=24 \text { from } \\
\text { Europe Age, } \\
\text { mean } \pm \text { SD: } \\
91.9 \pm 4.1 \\
70 \% \text { women }\end{array}$ & Institutionalized & Fried's criteria [2] & $\begin{array}{l}\text { Multi-component PRT } \\
12 \text { weeks } \\
2 / \text { week } \\
40 \text { min/session } \\
8-10 \text { repetitions } \\
40-60 \% \text { 1-RM } \\
\text { Two exercises for the leg } \\
\text { extensor muscles } \\
\text { (bilateral leg extensionand } \\
\text { bilateral knee extension } \\
\text { muscles) and one exercise } \\
\text { for upper limbs (seated } \\
\text { bench press), performed on } \\
\text { a resistance variable exercise } \\
\text { machine } \\
\text { Upper and lower extremities }\end{array}$ & $\begin{array}{l}\text { Falls: Incidence } \\
\text { Mobility: } 5 \text { meter walking tests at } \\
\text { their habitual speed; TUG; chair } \\
\text { rising ability (the most rises in } 30 \mathrm{sec} \text { ) } \\
\text { Balance: FICSIT-4 } \\
\text { Functional disability: } \\
\text { ADLs using BI } \\
\text { Strength: Isometric } \\
\text { upper and lower limb muscle } \\
\text { strength } \\
\text { Body composition: fat muscle } \\
\text { infiltration }\end{array}$ & $\begin{array}{l}\text { Exercise training significantly } \\
\text { reduced the incidence of falls } \\
(d=2.71) \\
\text { Walking ability did not change } \\
\text { with the intervention } \\
\text { Exercise training } \\
\text { significantly improved the time } \\
\text { spent on the TUG ( } d=0.42) \\
\text { Significant change in the } \\
\text { chair-rising ability test in the } \\
\text { intervention group ( } d=0.89) \\
\text { Exercise training improved } \\
\text { balance ( } d=0.72) \\
\text { Exercise training improved } \\
\text { functional } \\
\text { ability ( } d=1.17) \\
\text { Significant increase in knee } \\
\text { extension with the intervention } \\
(d=1.74)\end{array}$ \\
\hline
\end{tabular}


Table $\mathbf{2}$ Characteristics of the included studies (Continued)

\begin{tabular}{|c|c|c|c|c|c|c|}
\hline $\begin{array}{l}\text { Faber } \\
2006 \text { [32] }\end{array}$ & $\begin{array}{l}n=238 \text { from } \\
\text { Europe Age, } \\
\text { mean } \pm \text { SD: } \\
84.9 \pm 6.0 \\
79 \% \text { women }\end{array}$ & Institutionalized & $\begin{array}{l}\text { Frailty indicators adapted } \\
\text { from Fried's criteria [2] }\end{array}$ & $\begin{array}{l}\text { Multi-component functional } \\
\text { walking and in balance } \\
\text { exercises } \\
20 \text { weeks } \\
1 / \text { week for } 4 \text { weeks } \\
2 / \text { week for } 16 \text { weeks } \\
90 \text { min/session } \\
\text { Exercise without machines } \\
\text { focused on balance, mobility, } \\
\text { and transfer training. They } \\
\text { included standing up from a } \\
\text { chair, reaching and stepping } \\
\text { forward and sideward, heel and } \\
\text { toe stands, walking and turning, } \\
\text { stepping on and over an obstacle, } \\
\text { staircase walking, tandem foot } \\
\text { standing, and single-limb standing } \\
\text { Lower extremities } \\
\text { Tailored to the needs of each } \\
\text { participant }\end{array}$ & $\begin{array}{l}\text { Falls: incidence } \\
\text { Mobility: POMA; walking } \\
\text { tests: } 6 \text { meters as fast as possible; } \\
\text { TUG; chair rising ability } \\
\text { (the time needed to stand up } \\
\text { and sit down } 5 \text { consecutive } \\
\text { times as fast as possible) } \\
\text { Balance: POMA; FICSIT-4 } \\
\text { Functional disability: } \\
\text { ADL and instrumental ADL } \\
\text { using GARS }\end{array}$ & $\begin{array}{l}\text { Exercise training significantly } \\
\text { reduced the incidence of falls } \\
\text { in the pre-frail elderly sample } \\
\text { In the frail subgroup, the risk } \\
\text { becoming a faller increased } \\
\text { with the intervention } \\
\text { Positive effect of the } \\
\text { intervention on mobility in th } \\
\text { pre-frail subgroup. In the frail } \\
\text { subgroup, mobility worseneo } \\
\text { after the intervention } \\
\text { Small, but significant, positive } \\
\text { intervention effect in POMA } \\
\text { score in the exercise group, } \\
\text { compared with the control } \\
\text { group } \\
\text { Exercise training showed no } \\
\text { effect on functional ability }\end{array}$ \\
\hline $\begin{array}{l}\text { Fairhall } \\
2014 \text { [33] }\end{array}$ & $\begin{array}{l}n=241 \text { from } \\
\text { Australia/ } \\
\text { Oceania Age, } \\
\text { mean } \pm \text { SD: } \\
83.3 \pm 5.9 \\
68 \% \text { women }\end{array}$ & $\begin{array}{l}\text { Community } \\
\text { dwelling }\end{array}$ & Fried's criteria [2] & $\begin{array}{l}\text { Multi-component exercise intervention: } \\
\text { Home program of balance and lower } \\
\text { limb training based on the WEBB } \\
\text { program } \\
12 \text { months } \\
\text { 3-5/week } \\
20-30 \text { min/session } \\
\text { Exercises without machines } \\
\text { Lower extremities }\end{array}$ & $\begin{array}{l}\text { Falls: incidence; risk of falls } \\
\text { (Physiological Profile Assessment } \\
\text { [PPA]; short physical performance } \\
\text { battery [SPPB]); 4-m walking tests } \\
\text { Strength: Lower body strength } \\
\text { (knee-extension strength as a } \\
\text { component of the PPA) }\end{array}$ & $\begin{array}{l}\text { Exercise training did not } \\
\text { significantly reduce the } \\
\text { incidence of falls } \\
\text { Exercise training found a } \\
\text { better postural sway } \\
(d=0.09) \\
\text { Significant increase in leg } \\
\text { muscle extension with the } \\
\text { intervention ( } d=0.03)\end{array}$ \\
\hline
\end{tabular}


Table $\mathbf{2}$ Characteristics of the included studies (Continued)

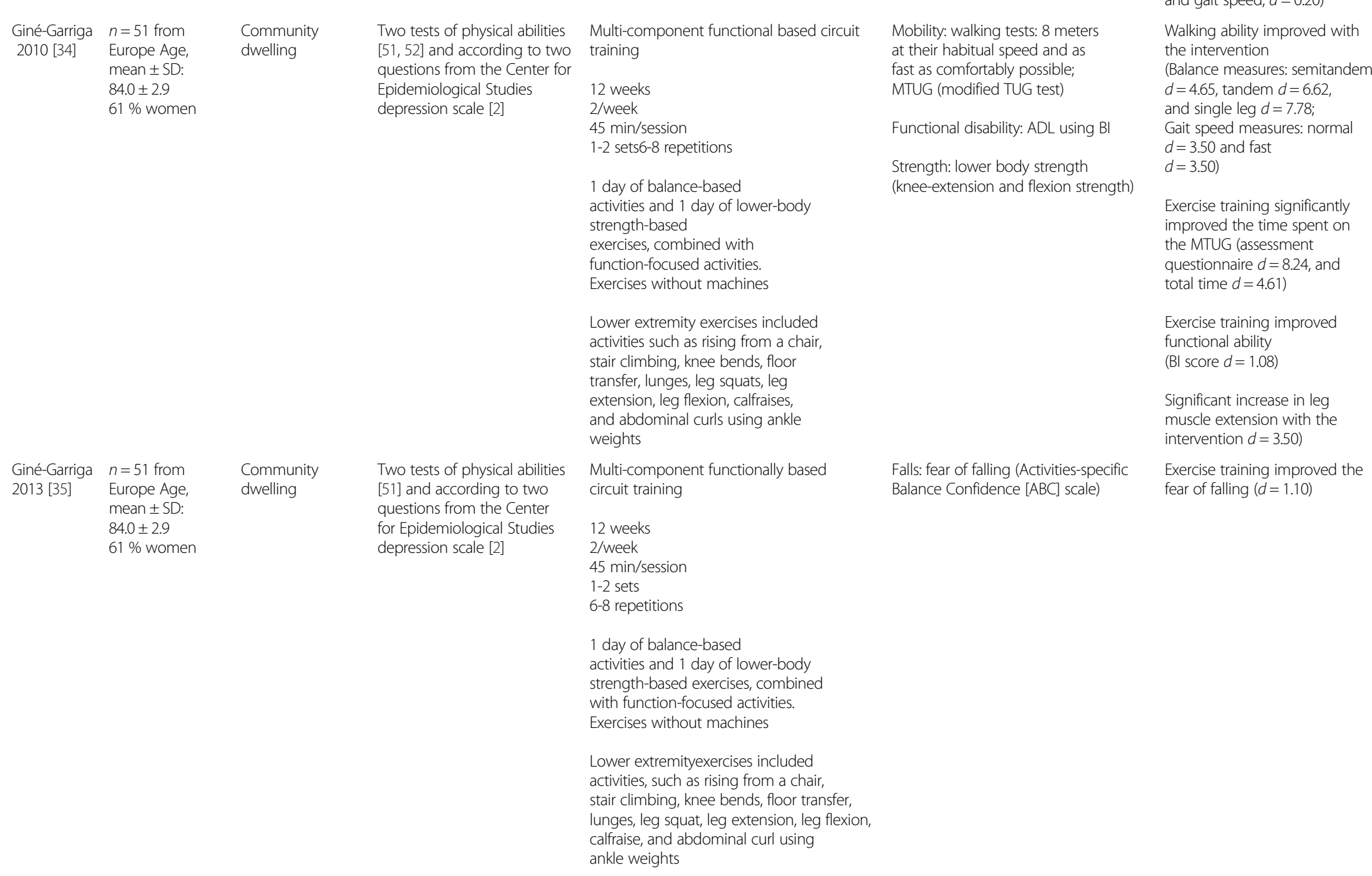


Table $\mathbf{2}$ Characteristics of the included studies (Continued)

Kim $2015 \quad N=131$ from Asia Community $\quad$ Fried's criteria [2]

$\operatorname{Kim}_{[37} 2015$

$80.7 \pm 2.8$

Fried's criteria [2]

$100 \%$

12 weeks

2/week

$60 \mathrm{~min} / \mathrm{session}$

30 minutes of strengthening exercises plus

20 minutes

of balance and gait training

Strength exercises performed in progressive

sequence from the seated to standing

positions,and progressive resistance

was applied through

Thera-bands, with increasing repetition

with each exercise

Lower extremitiesconsisted of

leg extensions, hip flexions, and

more. Upper body exercises included

double-arm pull downs, bicep curls,

and others

$\begin{array}{llll}\text { Latham } & n=243 \text { from } & \text { Teaching hospitals } & \text { Winograd's frailty } \\ \text { 2003 [36] } & \begin{array}{l}\text { Australia/Oceania } \\ \text { Age, mean } \pm \text { SD: }\end{array} & \\ & 79.1 \pm 6.9 & \\ & 53 \% \text { women } & & \end{array}$

Home-based resistance training

20 weeks

3/week

Initial goa:

3 sets

8 repetitions

30-40\% 1RM for

2 weeks

Final goal:3 sets

8 repetitions

60-80\% 1RM

Accomplished goal:

3 sets

8 repetitions

$51 \% 1 \mathrm{RM} \pm 13 \%$ 
Table $\mathbf{2}$ Characteristics of the included studies (Continued)

Adjustable ankle cuff

weights

Lower extremities

Body weight resistance training _ Mobility: 10 meter walking tests at their Walking ability improved with

10 weeks

$3 /$ week

$60 \mathrm{~min} / \mathrm{session}$

$60 \mathrm{~min} /$ session
3 sets 8 repetitions

$70 \% 1 \mathrm{RM}$

Ankle weights with loads ranging

from 0.5 to $3 \mathrm{~kg}$

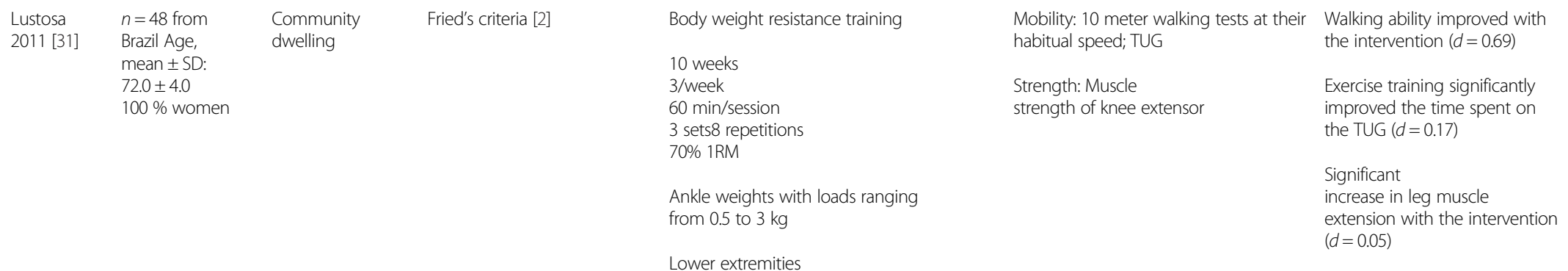

$d=$ Cohen's $d$ (effect size). A value of 0.2 indicates a small effect, 0.5 a medium effect and 0.8 a large effect [25]. PRT progressive resistance exercise training, 1-RM one-repetition maximum, WEBB weight-bearing for

better balance program, DEXA body dual energy x-ray absorptiometry FFM fat-free mass, FICSIT-4 frailty and injuries: cooperative studies of intervention techniques-4 static balance tests, BI Barthel index, ADL activities of daily living, POMA performance oriented mobility assessment, TUG time up-and-go test, GARS Groningen activity restriction scale, PPA physiological profile assessment, SPPB short physical performance battery, MTUG modified TUG test, $A B C$ activities-specific balance confidence scale, $B B S$ Berg balance scale, $F F M$ fat-free mas 
activities, and balance exercises, consisting of exercises derived from principles of Tai Chi [32]; and two applied a functional-based circuit training (FCT) program, being a combination of functional balance and lower-body strength exercises [34, 35]. The remaining three trials used non-multi-component programs, based on strength interventions [31, 36, 37].

The intervention lasted less than 6 months in seven of the trials [13, 31, 32, 34-37], 9 months in another trial [38], and 1 year in the last one [33]. The frequency of the training programs ranged from 2 to 3 times per week in almost all of the trials, except for one, which ranged from 3 to 5 times per week [33]. All but one study [36] reported the length of each session, ranging from 20 to $30 \mathrm{~min}$ [33] to $60-90$ min $[32,37,38]$. Eight $[13,31,32,34-38]$ of the nine [33] selected articles provided a detailed description of the program with regard to the intensity of the exercise intervention. Two of the trials used a weightlifting machine $[13,38]$. In one of them, the participants started with an initial configuration of 1-2 sets of 6-8 repetitions of each exercise at $65 \%$ of their one-repetition maximum (1-RM) with the goal of three sets of 8-12 repetitions of each exercise at $40-60 \%$ 1-RM [38], and in the other, the participants underwent a configuration of $8-10$ repetitions of each exercise at 40-60 \% 1-RM [13]. Two other trials used functional strength exercises without the help of any machine $[34,35]$. Both of them encompassed exercises such as rising from a chair, stair climbing, knee bends, floor transfer, lunges, leg squats, leg extension, leg flexion, calf raises, and abdominal curls using ankle weights. The configuration of the exercises was $1-2$ sets of $6-8$ repetitions for each exercise. Two of the trials employed ankle weights as a core of the training program $[31,36]$. In one of them, the participants underwent a configuration of three sets of eight repetitions of each exercise with a final goal set at $60-80 \%$ of their 1-RM (initial goal set at $30-40 \% 1$ $\mathrm{RM}$, accomplished goal $51 \pm 13 \% 1-\mathrm{RM}$ ) [36], and in the other, the participants underwent a configuration of three sets of eight repetitions of each exercise at $70 \%$ $1-\mathrm{RM}$ with loads ranging from 0.5 to $3 \mathrm{~kg}$ [31]. One of the trials used Thera-bands as a nucleus of the training program [37]. Lower and upper body exercises consisted of leg extensions, hip flexions, double-arm pull downs, bicep curls, and others. In this trial, milk fat globule membrane (MFGM) supplementation was also used to study its combined and separate effects with exercise training. Finally, one of the trials was designed to prevent falls with two programs: a functional walking program consisting of ten exercises focusing on balance, mobility, and transfer training, such as standing up from a chair, reaching and stepping forward and sideward, heel and toe stands, walking and turning, stepping on and over an obstacle, staircase walking, tandem foot standing, and single-limb standing; and an in balance program inspired in Tai-chi [32].
The intervention was targeted to the upper and lower extremities in three of the studies $[13,37,38]$ and to the lower extremities in the remaining six [31-36]. In only two of the trials, the intervention was tailored to the needs of the participants [32, 33].

\section{Outcome measurements \\ Falls}

Falls were examined in five studies $[13,32,33,35,36]$ by measuring the incidence of falls $[13,32,33,36]$, risk of falls [33], and fear of falling [35]. The effects of exercises on the incidence of falls were controversial among the studies. In two of them [13, 32], falls were significantly reduced after exercise training, at least in the pre-frail elderly sample [32], but not in the frail subgroup, in which the risk of becoming a faller increased with the intervention [32]. In two other trials, no significant effects of the training were found in the incidence of falls $[33,36]$. The only study considering the risk of falls found better effects on risk factors for falls with the intervention [33]. Finally, the fear of falling also improved after the intervention [35].

\section{Mobility}

Several aspects of mobility were measured in six of the nine trials [13, 31, 32, 34, 36, 37]. One study used four combined standardized physical performance tests to develop a single measurement of mobility [32]. The authors found different results depending on the sample subgroup. In the frail subgroup, the physical performance score was lower after the intervention, whereas there was a positive effect of the intervention on the physical performance score in the pre-frail subgroup. The other five trials used individualized standard measurements of mobility [13, 31, 34, 36, 37]. All of them measured walking ability with several variations of walking tests, ranging from walking 4 to $10 \mathrm{~m}$ at habitual speed or as rapidly as comfortably possible. While in two of the trials, walking ability improved with the intervention $[31,34]$, in the other three trials, there were no changes in the IG [13,36,37], with one of these trials finding a significant decrease in the gait velocity of the CTL [13]. Mobility using the Timed up-and-go test (TUG) was measured in five trials [13, 31, 34, 36, 37]. While in four of them, a significant improvement was found in the time spent on the TUG test in the IG compared to the CTL $[13,31,34,37]$, one study found no effect of the intervention on this measurement [36]. Chair-rising ability was measured in one of the four studies using individualized standard measurements of mobility [13], finding a significant increase in performance on this test in the IG and no changes in the CTL. One study also employed the Performance Oriented Mobility Assessment (POMA) as a measurement of mobility [36]. It found a 
small, but significant, positive effect of the intervention on the POMA score in the IG, compared with the CTL.

\section{Balance}

Balance was measured in three of the selected trials $[13,32,36]$. The first one used the Frailty and Injuries: Cooperative Studies of Intervention Techniques-4 (FICSIT-4) static balance tests [13], the second trial used the FICSIT-4 tests of static balance, but the result was reported as a combined measurement of four standardized physical performance tests [32] (the result of this combined measurement was discussed in the mobility section), and the last one used the Berg Balance Scale (BBS) [36]. After training exercises, balance improved in one of the trials [13], and in the others, balance was not affected by the exercise intervention [36].

\section{Functional ability}

Functional ability was measured in four of the nine trials [13, 32, 34, 36]. Three used the Barthel Index (BI) $[13,34,36]$ (one of them also used the Adelaide Activity Profiles [36]), and the other used the Groningen Activity Restriction Scale (GARS) [32]. Interventions showed positive results in improving functional ability in two of the trials [13,34], whereas in the other two trials, no effects of the intervention were found in this measurement $[32,36]$.

\section{Muscle strength}

Seven of the nine trials measured muscle strength [13, 31, 33, 34, 36-38]. Lower limb strength was measured in all of them, measuring knee extension. Knee flexion was measured in two of the trials [34, 38], and hip flexion was measured in one trial [13]. Upper muscle strength was measured in two trials only $[13,37]$. One of the trials measured the grip strength in the right hand [13], and the other trial measured grip strength in the dominant hand. Five of the seven trials measuring knee extension showed a significant increase in this measurement with the intervention [13, 31, 33, 34, 38]. Only two trials showed no effect of the intervention on this measurement [36, 37]. None of the trials measuring flexion strength $[34,38]$ found any improvement with the intervention. Similarly, the two trials measuring upper muscle strength found no significant changes with the intervention $[13,37]$.

\section{Body composition}

Two studies examined body composition [37, 38], measuring it with total body dual energy $x$-ray absorptiometry (DEXA). While one of these studies [38] found that low to moderate intensity PRT induced greater increases in total and regional fat-free mass (FFM) and isokinetic muscle strength but no changes in fat mass, compared to a home-based, low intensity exercise program, the other study [37] did not have any effect on this parameter. Another study [13] examined muscle tissue attenuation (indicative of fat infiltration) using computed tomography scans at the midthigh of the left quadriceps femoris using a 64-row CT scanner. The results of this study revealed that a multi-component exercise program including muscle power training induced a decrease in muscle fat infiltration.

\section{Frailty status}

One study examined frailty status [37], which was defined as the presence of three or more of the five frailty criteria [2]. Reversal of frailty was defined as the percentage of subjects who were defined as frail at baseline but who decreased to two or below at post-intervention. This study found that 3 months of exercise had an effect on frailty status, reversing the frailty status in comparison to the CTL group. However, when the 3-month exercise was combined with the nutrition supplementation program (MFGM), the effect on frailty reversal was maximized.

\section{Discussion}

This systematic review, which aimed to retrieve recent evidence examining the potential role of physical exercise interventions in frail older adults, provided evidence that physical exercise has positive effects on most of the outcome measurements included in this current revision. There were, however, large differences between studies with regard to the effect sizes. Except for one trial [36], consistent findings were found regarding the effects of the evaluated exercise programs on frailty and/or physical capacity and/or functional capacity. To perform this review, we used strict criteria to define frailty in older people, indicating that trials including the word "frail" in the title or in the abstract, if not rigorously defined, were not included. Due to the lack of consensus about measurements for detecting frailty, the uniformity of the target groups might have been reduced; however, all of the trials were considered to have sufficient methodological quality to be included in this review.

Two of the trials applied single lower extremity strength training [31, 36]. While one of them showed significant improvements in mobility and strength (although with a trivial practical significance) [31], the other one did not find any effects on falls, mobility, balance, functional ability or strength [36]. These apparently negative results could be explained because of the limited duration of the program (only 10 weeks) or because the exercise program addressed one muscle group (quadriceps), thus limiting greater improvements in performance. The contradicting results observed in the trials using only strength training of the lower extremities could be sorted out by including strength training as part of a more complete program, such as a multi-component exercise program. 
In this review, the trials with multi-component physical exercise programs focused on resistance and/or balance and/or flexibility exercises [13, 33-35, 38] (the exercise program of Faber et al. [32] did not include strength training as part of the multi-component exercise program). All of the trials reported statistically significant effects for falls, mobility, balance, functional ability, muscle strength and body composition, except for one trial that found no changes in walking ability with the intervention [13] and another trial in which exercise training did not significantly reduce the incidence of falls [33]. Although most of the literature in this field has supported that multi-component exercises appear to be the most effective interventions to improve the overall health status of frail elderly people [13, 39], our search strategy focused on studies with a variety of exercise programs and with a broad range of methods to evaluate the results. Because of this heterogeneity, it is difficult to draw a conclusion about the single best program to apply for a specific frail population. It could be suggested that programs targeting more than one physical component (strength, endurance, balance, flexibility) promote better performance with regard to the global functional capacity of older adults. Moreover, the variety of interventions in the CTL (regular care, low intensity exercises, standard exercises for activities of daily living, etc.), although improving the accuracy and generalization of external data, could also influence the specific effects of training, compared with other factors. Consequently, this variety could act as a confounder to determine the best intervention program.

The literature has shown that participation in regular physical activity protects against diverse components of frailty syndrome [40], improving the quality of life of older people [35] by increasing balance and mobility and reducing falls, as well as institutionalization, hospitalization and mortality. Not all of the studies analyzed in this review included interventions only addressing muscle strengthening, but they also combined programs addressing activities of daily living, walking, balance, nutrition supplementation, and others, potentially increasing the beneficial effects of the physical activity aiming to improve frailty. All of the reviewed studies apart from one [36] showed an increase in muscle strength and muscle extension, along with improvements in mobility, balance, functional capacity, and frailty status, suggesting positive effects on frailty syndrome. However, the clinical significance of some results is low or very low, with small to very small effect sizes [31, 33].

A critical component of resistance training programs is the intensity or the amount of weight being lifted. Four of the studies offered a detailed explanation of their programs $[13,31,36,38]$, with the majority of the studies using three sets of eight 1-RM at $40-80 \%$, with rest intervals. Research has shown that intensities ranging from 70 to $95 \%$ of 1 RM significantly increase muscle strength [41]. In the trial of Latham et al. [36] and as a result of complaints from participants about muscle soreness, the therapists decreased the intensity of the weights to $30-40 \%$ of $1-R M$ during the first 2 weeks of the program. This change could theoretically have moved the program away from the primary goal of strength training and could be the reason that it did not find significant differences between the CTL and the IG. In any case, this result suggested that, despite frailty conditions in the elderly, they are able to participate in a personalized strength training program that considers their own limits. This fact is very important because the exercises generally recommended to the elderly population used to be intense and tiring.

Obesity is a condition that exacerbates with age, producing a decline in the physical function of older adults and causing frailty and a reduction in the quality of life [42, 43]. Numerous studies have consistently shown that exercise benefits the body composition of healthy older adults [44]. Two of the nine trials included in this review studied the effects of PRT on the body composition of frail elderly people [13, 38], finding that the intervention induced greater increases in total and regional FFM and a decrease in the fat muscle infiltration, but no changes in fat mass. However, these results showed a small effect size. Moreover, one of the trials studied strengthening exercises plus balance and gait training in body composition [37], finding no significant effects on this measurement.

One of the nine studies included in this review had the specific goal of studying the reversal status in Fried's frailty criteria [37]. This trial, which specifically investigated the combined and separate effects of exercise and MFGM supplementation on frailty, found that exercise training improved frailty status. However, the combined effect of exercise plus nutritional supplementation is perhaps the most beneficial option to improve frailty in elderly women. Although there has been increased interest regarding the value of nutritional supplementation for physical parameters [45], the vast majority of articles are performed in young adults. The trial of Kim et al. (2015) [37] confirmed the added value of nutritional supplementation on exercise interventions in the elderly. For the optimal effects of exercise, it is important that older people adhere to the prescribed exercise program [46]. Although we did not study the adherence of elderly people to the prescribed exercise programs, most of the studies included in this review reported small withdrawals from the exercise programs (lack of adherence) [13, 33-36, 38]. This fact could be mainly due to the typology of the participants - frail elderly people - or because adherence to programs is known to decrease in older people when more exercises are added to the program [47]. 
Although there have been several systematic reviews published addressing the issue of the benefits of exercise in frail elderly people [48-50], a decisive conclusion about the optimal program to improve the global capacity of frail elders remains unclear. Because of that, and because the topic of frailty is characterized by a high level of scientific publications, updatings to this literature are mandatory. With this systematic review, we provided an update of the literature. Of the three systematic reviews previously mentioned, two performed meta-analyses [49, 50]. Chou et al. [49] aimed with a meta-analysis to determine the effects of exercise training on the physical functions, performance of ADL, and quality of life of frail elderly people. Similar to our conclusions, they determined that exercise was beneficial in improving physical function and performance of ADLs. The meta-analysis of De Vries et al. [50], aimed to assess the effects of physical exercise interventions on mobility, physical functioning, physical activity and quality of life in elderly people with mobility problems, disability and/or multi-morbidity. Similar to us, but also including nonfrail and prefrail elders, they concluded that physical exercise interventions improved mobility and physical functioning. The systematic review of Cadore et al. [48] studied the effects of exercise programs on muscle strength, balance, gait ability, and the risk of falls, finding that multi-component interventions seemed to be the best strategy for improving those outcomes in frail elderly people.

Although this review presented well-defined inclusion criteria, we did find several methodological limitations. Considering the characteristics of the interventions and the outcome measurements, we observed great variety among the different studies. The most recommended intervention in frail subjects was multi-component training, which offers a broad variety of exercises with an enormous number of possibilities and combinations. Regarding the outcome measurements of the different trials, we should say they are the most commonly used measurements to assess the benefits of physical activity in frail elderly people. Additional limitations of this review were the few studies performed in institutionalized and hospital settings to perform significant comparisons among them and the small sample sizes of some of the trials, not only making the number of subjects in the IG and the GTL small, but also limiting the strength of the conclusions. Finally, another limitation of the current review was the lack of consensus in the definition of frailty and the use of various different criteria to define frailty, which reduced the uniformity of the target groups.

Although this systematic review provided evidence that physical exercise has positive effects on frail older adults, we should consider that there was great variety among the studies concerning sample size, degree of frailty, types of interventions and types of assessments.
Besides, some findings should be interpreted cautiously because power analysis showed very small or small effect sizes. Moreover, the absence of changes in some of the outcomes explored in this analysis could indicate that exercise prescriptions must be carefully adapted to the sample of frail older people. A strong point of this analysis is that it is focused on a population of frail elderly people, defined with a clear theoretical or operational definition of frailty.

\section{Conclusions}

This systematic review showed that exercise training addressed to frail elderly people could improve several aspects of their physical function. Although we suggested that multi-component exercise programs including some type of resistance training would promote better performance in the global functional capacity of frail older adults, the optimal program remains unclear. More studies regarding this topic and with this specific population are needed to determine the most favorable exercise program.

\section{Additional file}

Additional file 1: PRISMA 2009 Checklist. (DOC 62 kb)

\begin{abstract}
Abbreviations
1-RM: One-Repetition Maximum; ABC: activities-specific balance confidence scale; ACSM: American College of Sports Medicine; ADL: activities of daily living; BBS: Berg Balance Scale; BI: Barthel Index; CTL: control group; DEXA: body dual energy $x$-ray absorptiometry; FCT: functional-based circuit training program; FFM: fat-free mass; FICSIT-4: Frailty and Injuries: Cooperative Studies of Intervention Techniques-4 (FICSIT-4) static balance tests; GARS: Groningen Activity Restriction Scale; IG: intervention group; MTUG: modified timed up-and-go test; PEDro: physiotherapy evidence database scale; POMA: Performance Oriented Mobility Assessment; PPA: physiological profile assessment; PRT: progressive resistance exercise training; RCT: randomized and controlled clinical trials; SPPB: short physical performance battery; TUG: time up-and-go test; WEBB: weight-bearing for better balance program.
\end{abstract}

\section{Competing interests}

The authors declare that they have no competing interests.

\section{Authors' contributions}

JCMC, CDL and AM contributed to the conception and design of the study, along with critical revision of the manuscript before the final submission. CDL, CGP and TL performed the search and analyzed the articles. CDL and JCMC contributed to the analysis and interpretation of the data, along with the drafting of the manuscript. All the authors revised the final version of the manuscript and approved its submission to be published.

\section{Funding}

The authors received no financial support for the research, authorship, and/ or publication of this article.

\section{Author details}

${ }^{1}$ Research, Development and Innovation Department, Gerontological Complex La Milagrosa, Provincial Association of Pensioners and Retired People (UDP) from A Coruña, Avenida de Cádiz-5, E-15008 A Coruña, Spain. ${ }^{2}$ Gerontology Research Group, Department of Medicine, Faculty of Health Sciences, Universidade da Coruña, Campus de Oza, E-15071 A Coruña, Spain. 
Received: 21 July 2015 Accepted: 23 November 2015 Published online: 02 December 2015

\section{References}

1. World Health Organization. Active ageing: a policy framework. Geneva: World Health Organization; 2002. whqlibdoc.who.int/hq/2002/who_nmh_ nph_02.8.pdf. Accessed 14 May 2015.

2. Fried LP, Tangen CM, Walston J, Newman AB, Hirsch C, Gottdiener J, et al. Frailty in older adults: evidence for a phenotype. J Gerontol A Biol Sci Med Sci. 2001;56(3):146-56.

3. Puts MT, Lips P, Deeg DJ. Sex Differences in the Risk of Frailty for Mortality Independent of Disability and Chronic Diseases. J Am Geriatr Soc. 2005; 53(1):40-7.

4. Mitnitski AB, Graham JE, Mogilner AJ, Rockwood K. Frailty, fitness and late-life mortality in relation to chronological and biological age. BMC Geriatr. 2002;2:1.

5. Curcio $\mathrm{CL}$, Henao GM, Gomez F. Frailty among rural elderly adults. BMC Geriatr. 2014;14:2.

6. Rockwood K. What would make a definition of frailty successful? Age Ageing. 2005:34(5):432-4

7. Gobbens RJ, Luijkx KG, Wijnen-Sponselee MT, Schols JM. Toward a conceptual definition of frail community dwelling older people. Nurs Outlook. 2010;58(2):76-86

8. Fried LP, Ferrucci L, Darer J, Williamson JD, Anderson G. Untangling the concepts of disability, frailty, and comorbidity: implications for improved targeting and care. J Gerontol A Biol Sci Med Sci. 2004;59(3):255-63.

9. Cutler DM. Declining disability among the elderly. Health Aff (Millwood). 2001;20(6):11-27

10. Gill TM, Gahbauer EA, Allore HG, Han L. Transitions between frailty states among community-living older persons. Arch Intern Med. 2006;166(4):418-23.

11. American College of Sports Medicine, Chodzko-Zajko WJ, Proctor DN, Fiatarone Singh MA, Minson CT, Nigg CR, et al. American college of sports medicine position stand, Exercise and physical activity for older adults. Med Sci Sports Exerc. 2009;41(7):1510-30.

12. Binder EF, Schechtman KB, Ehsani AA, Steger-May K, Brown M, Sinacore DR, et al. Effects of exercise training on frailty in community-dwelling older adults: Results of a randomized, controlled trial. J Am Geriatr Soc. 2002; 50(12):1921-8

13. Cadore EL, Casas-Herrero A, Zambom-Ferraresi F, Idoate F, Millor N, Gomez M, et al. Multicomponent exercises including muscle power training enhance muscle mass, power output, and functional outcomes in institutionalized frail nonagenarians. Age (Dordr). 2014;36(2):773-85.

14. Inokuchi S, Matsusaka N, Hayashi T, Shindo H. Feasibility and effectiveness of a nurse-led community exercise programme for prevention of falls among frail elderly people: A multi-centre controlled trial. J Rehabil Med. 2007:39(6):479-85.

15. Dionigi R. Resistance training and older adults' beliefs about psychological benefits: The importance of self-efficacy and social interaction. J Sport Exerc Psychol. 2007;29(6):723-46.

16. Landi F, Abbatecola A, Provinciali M, Corsonello A, Bustacchini S, Manigrasso L, et al. Moving against frailty: Does physical activity matter? Biogerontology. 2010;11(5):537-45.

17. Kramer AF, Colcombe SJ, McAuley E, Scalf PE, Erickson KI. Fitness, aging and neurocognitive function. Neurobiol Aging. 2005;26 Suppl 1:124-7.

18. Arbab-Zadeh A, Dijk E, Prasad A, Fu Q, Torres P, Zhang R, et al. Effect of aging and physical activity on left ventricular compliance. Circulation. 2004; 110(13):1799-805.

19. Fletcher GF, Balady G, Blair SN, Blumenthal J, Caspersen C, Chaitman B, et al. Statement on exercise: Benefits and recommendations for physical activity programs for all americans. A statement for health professionals by the committee on exercise and cardiac rehabilitation of the council on clinical cardiology, American heart association. Circulation. 1996;94(4):857-62.

20. Ram FS, Robinson SM, Black PN. Effects of physical training in asthma: A systematic review. Br J Sports Med. 2000;34(3):162-7.

21. Hiroyuki S, Uchiyama Y, Kakurai S. Specific effects of balance and gait exercises on physical function among the frail elderly. Clin Rehabil. 2003; 17(15):472-9.

22. Madureira MM, Takayama L, Gallinaro AL, Caparbo VF, Costa RA, Pereira RM. Balance training program is highly effective in improving functional status and reducing the risk of falls in elderly women with osteoporosis: A randomized controlled trial. Osteoporos Int. 2007;18(4):419-25.
23. Peri K, Kerse N, Robinson E, Parsons M, Parsons J, Latham N. Does functionally based activity make a difference to health status and mobility? A randomised controlled trial in residential care facilities (The Promoting Independent Living Study; PILS). Age Ageing. 2008;37(1):57-63.

24. Hruda KV, Hicks AL, McCartney N. Training for muscle power in older adults: Effects on functional abilities. Can J Appl Physiol. 2003;28(2):178-89.

25. Cohen J. Statistical power analysis for the behavioural sciences. 2nd ed. Hillsdale: Erlbaum; 1988.

26. Maher CG, Sherrington C, Herbert RD, Moseley AM, Elkins M. Reliability of the PEDro scale for rating quality of randomized controlled trials. Phys Ther. 2003;83(8):713-21.

27. Verhagen AP, de Vet HC, de Bie RA, Kessels AG, Boers M, Bouter LM, et al. The Delphi list: a criteria list for quality assessment of randomized clinical trials for conducting systematic reviews developed by Delphi consensus. J Clin Epidemiol. 1998;51(12):1235-41.

28. Foley NC, Bhogal SK, Teasell RW, Bureau Y, Speechley MR. Estimates of quality and reliability with the physiotherapy evidence-based database scale to assess the methodology of randomized controlled trials of pharmacological and nonpharmacological interventions. Phys Ther. 2006;86(6):817-24.

29. Liberati A, Altman DG, Tetzlaff J, Mulrow C, Gøtzsche PC, loannidis JP, et al. The PRISMA statement for reporting systematic reviews and meta-analyses of studies that evaluate healthcare interventions: explanation and elaboration. BMJ. 2009:339:b2700.

30. Moher D, Liberati A, Tetzlaff J, Altman DG, PRISMA Group. Preferred reporting items for systematic reviews and meta-analyses: the PRISMA statement. J Clin Epidemiol. 2009;62(10):1006-12.

31. Lustosa LP, Silva JP, Coelho FM, Pereira DS, Parentoni AN, Pereira LS. Impact of resistance exercise program on functional capacity and muscular strength of knee extensor in pre-frail community-dwelling older women: a randomized crossover trial. Rev Bras Fisioter. 2011;15(4):318-24.

32. Faber MJ, Bosscher RJ, Chin A, Paw MJ, van Wieringen PC. Effects of exercise programs on falls and mobility in frail and pre-frail older adults: A multicenter randomized controlled trial. Arch Phys Med Rehabil. 2006;87(7):885-96.

33. Fairhall N, Sherrington C, Lord SR, Kurrle SE, Langron C, Lockwood K, et al. Effect of a multifactorial, interdisciplinary intervention on risk factors for falls and fall rate in frail older people: a randomised controlled trial. Age Ageing. 2014;43(5):616-22.

34. Giné-Garriga $M$, Guerra $M$, Pagès $E$, Manini $T M$, Jiménez $R$, Unnithan VB. The effect of functional circuit training on physical frailty in frail older adults: a randomized controlled trial. J Aging Phys Act. 2010;18(4):401-24.

35. Giné-Garriga M, Guerra M, Unnithan VB. The effect of functional circuit training on self-reported fear of falling and health status in a group of physically frail older individuals: a randomized controlled trial. Aging Clin Exp Res. 2013;25(3):329-36.

36. Latham NK, Anderson CS, Lee A, Bennett DA, Moseley A, Cameron ID, et al. A randomized, controlled trial of quadriceps resistance exercise and vitamin D in frail older people: the Frailty Interventions Trial in Elderly Subjects (FITNESS). J Am Geriatr Soc. 2003;51(3):291-9.

37. Kim H, Suzuki T, Kim M, Kojima N, Ota N, Shimotoyodome A, et al. Effects of Exercise and Milk Fat Globule Membrane (MFGM) Supplementation on Body Composition, Physical Function, and Hematological Parameters in Community-Dwelling Frail Japanese Women: A Randomized Double Blind, Placebo-Controlled, Follow-Up Trial. PLoS One. 2015;10(2), e0116256.

38. Binder EF, Yarasheski KE, Steger-May K, Sinacore DR, Brown M, Schechtman KB, et al. Effects of progressive resistance training on body composition in frail older adults: results of a randomized, controlled trial. J Gerontol A Biol Sci Med Sci. 2005;60(11):1425-31.

39. Villareal DT, Smith Gl, Sinacore DR, Shah K, Mittendorfer B. Regular multicomponent exercise increases physical fitness and muscle protein anabolism in frail, obese, older adults. Obesity (Silver Spring). 2011;19(2): 312-8.

40. Peterson MJ, Giuliani C, Morey MC, Pieper CF, Evenson KR, Mercer V, et al. Physical activity as a preventative factor for frailty: the health, aging, and body composition study. Health, Aging and Body Composition Study Research Group. J Gerontol A Biol Sci Med Sci. 2009;64(1):61-8.

41. Moore DR, Burgomaster KA, Schofield LM, Gibala MJ, Sale DG, Phillips SM. Neuromuscular adaptations in human muscle following low intensity resistance training with vascular occlusion. Eur J Appl Physiol. 2004;92(4-5):399-406.

42. Blaum CS, Xue QL, Michelon E, Semba RD, Fried LP. The association between obesity and the frailty syndrome in older women: the Women's Health and Aging Studies. J Am Geriatr Soc. 2005;53(6):927-34. 
43. Villareal DT, Banks M, Siener C, Sinacore DR, Klein S. Physical frailty and body composition in obese elderly men and women. Obes Res. 2004; 12(6):913-20.

44. Campbell WW, Crim MC, Young VR, Evans WJ. Increased energy requirements and changes in body composition with resistance training in older adults. Am J Clin Nutr. 1994;60(2):167-75.

45. Wilkinson SB, Tarnopolsky MA, Macdonald MJ, Macdonald JR, Armstrong D, Phillips SM. Consumption of fluid skim milk promotes greater muscle protein accretion after resistance exercise than does consumption of an isonitrogenous and isoenergetic soy-protein beverage. Am J Clin Nutr. 2007; 85(4):1031-40.

46. Picorelli AM, Pereira LS, Pereira DS, Felício D, Sherrington C. Adherence to exercise programs for older people is influenced by program characteristics and personal factors: a systematic review. J Physiother. 2014;60(3):151-6.

47. Henry KD, Rosemond C, Eckert LB. Effect of number of home exercises on compliance and performance in adults over 65 years of age. Phys Ther. 1999:79(3):270-7.

48. Cadore EL, Rodríguez-Mañas L, Sinclair A, Izquierdo M. Effects of different exercise interventions on risk of falls, gait ability, and balance in physically frail older adults: a systematic review. Rejuvenation Res. 2013;16(2):105-14.

49. Chou $\mathrm{CH}$, Hwang $\mathrm{CL}$, Wu YT. Effect of exercise on physical function, daily living activities, and quality of life in the frail older adults: a meta-analysis. Arch Phys Med Rehabil. 2012;93(2):237-44.

50. de Vries NM, van Ravensberg CD, Hobbelen JS, Olde Rikkert MG, Staal JB, Nijhuis-van der Sanden MW. Effects of physical exercise therapy on mobility, physical functioning, physical activity and quality of life in community-dwelling older adults with impaired mobility, physical disability and/or multi-morbidity: a meta-analysis. Ageing Res Rev. 2012;11(1):136-49.

51. Gill TM, Baker DI, Gottschalk M, Peduzzi PN, Allore H, Byers A. A program to prevent functional decline in physically frail, elderly persons who live at home. N Engl J Med. 2002;347:1068-74.

52. Tinetti ME, Speechley M, Ginter SF. Risk factors for falls among elderly persons living in the community. N Engl J Med. 1988;319:1701-7.

53. Winograd $\mathrm{CH}$, Gerety MB, Chung M, Goldstein MK, Dominguez Jr F, Vallone R. Screening for frailty: Criteria and predictors of outcomes. J Am Geriatr Soc. 1991;39:778-84.

\section{Submit your next manuscript to BioMed Central and we will help you at every step:}

- We accept pre-submission inquiries

- Our selector tool helps you to find the most relevant journal

- We provide round the clock customer support

- Convenient online submission

- Thorough peer review

- Inclusion in PubMed and all major indexing services

- Maximum visibility for your research 